\title{
PESSOAS VIVENDO COM HIV: ESTRESSE E SUAS FORMAS DE ENFRENTAMENTO
}

\author{
Marcos Venícios de Oliveira Lopes* \\ Maria de Nazaré Oliveira Fraga**
}

\begin{abstract}
LOPES, M.V.de O.; FRAGA, M.de N.O. Pessoas vivendo com HIV: estresse e suas formas de enfrentamento. Rev.latino-am.enfermagem, Ribeirão Preto, v. 6, n. 4, p. 75-81, outubro 1998.
\end{abstract}

Estudo sobre a influência do estresse na vida da pessoa com HIV/AIDS, realizado com onze homens soropositivos, tendo por objetivo analisar entre o estresse e o cotidiano das pessoas soropositivas. Usando como técnica de coleta a entrevista, levantamos que muitos dos entrevistados já passaram ou vivenciam situações estressoras como: Mudanças sociais e sexuais, perdas materiais, solidão e medo da morte. As formas de enfrentamento do estresse variaram entre fuga, ficar alegre a todo custo e tentar esquecer. Concluímos que existe a necessidade de preparo para enfrentar o estresse, bem como uma intervenção efetiva dos profissionais de saúde nesta questão.

UNITERMOS: AIDS, estresse, HIV

\section{INTRODUÇÃO}

A Síndrome da Imunodeficiência Adquirida (AIDS) configura a grande pandemia da atualidade. Sua rápida disseminação levou ao pânico e a uma série de problemas sociais e psicológicos graves, não somente para a população geral, como também, e principalmente, para aqueles que se infectaram com o Vírus da Imunodeficiência Humana (HIV).

A falta de esclarecimento é, ainda hoje, a grande responsável por situações conflituosas pelas quais passam as pessoas que possuem algum tipo de doença sexualmente transmissível e, principalmente, aquelas que portam o HIV. Segundo PARKER et al. ${ }^{7}(1994$, p.283) "no Brasil, como em outros países, o período compreendido entre as últimas décadas do século passado e a grande guerra caracteriza-se pela constituição da percepção das doenças venéreas, especialmente da sífilis como grande perigo social". Desta forma, a população vem desenvolvendo um pensamento preconceituoso e discriminativo em torno das doenças sexualmente transmissíveis e a tudo aquilo que possa ter relação com as mesmas. Assim, não só as pessoas que comercializavam o próprio corpo, como também aquelas que contraíam qualquer tipo de doença por meio de relações sexuais, sentiam (e ainda hoje sentem) além da vergonha social, uma profunda auto-discriminação. No caso da AIDS, a ausência de uma cura e as dimensões alarmantes que vêm tomando a pandemia aumentam a angústia em torno da questão. Segundo MANN et al. ${ }^{6}$ (1993) a estimativa de infectados para o ano 2000 situase entre 38 e 110 milhões de infectados, uma estimativa três vezes mais alta que a da Organização Mundial da Saúde (OMS). Estes altos números refletem a falha nas estratégias de controle da disseminação do HIV.

Esta problemática de distribuição numérica aliada ao despreparo social para lidar com a questão têm trazido consequências gravíssimas para os portadores do HIV. Junto a estas dificuldades, existe o grave problema biológico causado pelo vírus. A imunodeficiência causada por este vírus é progressiva e atinge principalmente os linfócitos $\mathrm{T}$, responsáveis pela imunidade celular, tornando o indivíduo susceptível a várias infecções intercorrentes. Como afirmam COSTA et al. ${ }^{2}$ (1992, p.123), a AIDS “se caracteriza por produzir um quadro de deteriorização profunda, progressiva e irreversível da função imune que leva secundariamente ao desenvolvimento de infecções oportunistas". Uma grave conseqüência disso é que o número de condições clínicas que uma pessoa soropositiva pode apresentar é bastante elevado. Conforme afirmam GONDIM et al. ${ }^{4}$ (1993, p.05) "A infecção do corpo humano pelo HIV pode provocar mais de 70 condições patológicas diferentes (seja por infecção direta ou facilitando surtos de infecção oportunista)". Junto a esses problemas patológicos estão as alterações do sistema imune que se estabelecem de maneira anárquica com mudanças radicais no perfil imunológico das pessoas infectadas pelo vírus. Segundo ABBAS et al. ${ }^{1}(1995, \mathrm{p}$.

\footnotetext{
* Enfermeiro, mestrando em Enfermagem pela Universidade Federal do Ceará - UFC

** Enfermeira, doutora em Enfermagem, Professora do Departamento de Enfermagem da Universidade Federal do Ceará - UFC
} 
420) "a relação entre os linfócitos T CD4+ e linfócitos T CD8+ no sangue periférico é de aproximadamente de 2:1 nos indivíduos normais, mas ela está freqüentemente reduzida, para até 0,5 , em pacientes de AIDS". Ainda segundo estes autores outras alterações importantes ocorrem, tais como: Destruição de linfócitos T CD4+ não infectados devido a reação cruzada com proteínas virais; Bloqueio da interação dos linfócitos T CD4+ com a classe II do CHP, nas APCs; Prejuízos ao funcionamento dos macrófagos e células NK.

Somado aos aspectos acima, existem problemas relacionados ao tratamento que também afetam os portadores do HIV, como os diversos efeitos colaterais que, em muitos casos, levam o paciente a uma espécie de depressão psicológica causada por longos períodos de tratamento e constantes retornos ao hospital. Em muitos casos, isto se associa ao abandono pelos familiares, perda do emprego e o isolamento. O medo da morte é um outro fator relevante que leva a gravíssimos quadros de angústia. Tal medo pode ser considerado, de certa forma previsível, se levarmos em conta os números relacionados ao óbito, tomando como exemplo uma citação de MANN et al. ${ }^{6}$ (1993, p.02).

"No início de 1992, havia 12.9 milhões de pessoas no mundo inteiro (incluindo 4.7 milhões de mulheres, 7.1 milhões de homens e 1.1 milhão de crianças) infectadas pelo HIV. Cerca de um quinto (2.7 milhões, $21 \%$ ) desenvolveram AIDS; delas, mais de $90 \%$ (aproximadamente 2.5 milhões) morreram".

O medo e a angústia podem se tornar aumentados configurando uma situação estressante. Este tipo de aflição une-se ao comportamento social das demais pessoas fazendo com que a soropositividade para o HIV torne-se equivalente a uma sentença de morte. Nota-se com facilidade que a pessoa com HIV passa por um número muito grande de situações estressantes que segundo dados atuais podem contribuir para a deteriorização do sistema imune. O estresse, reação orgânica de origem psicofisiológica, surge a partir de agentes denominados estressores que segundo LIPP \& MALAGRIS 5 (1989, p. 281), se referem a "qualquer situação geradora de um estado emocional forte que leva a uma quebra da homeostase interna e exige alguma adaptação".

Os mesmos autores colocam que os estressores podem ser classificados de diversas maneiras (biogênicos e/ou psicossociais; internos ou externos etc.). O fato é que a partir do momento em que o número de estressores é grande ou intenso, o estresse se instala e desenvolvese em três fases: a) fase de alerta, primeiro contato com o estressor; b) fase de resistência, o organismo tenta restabelecer a homeostase; e c) fase de exaustão, pode ocorrer exaustão física e psicológica. Selye apud LIPP $\&$ MALAGRIS $^{5}$ (1989) afirma que a generalização da resposta ao estresse é realizada pela integração de dois grandes sistemas, o endócrino e o nervoso. Neste processo, os principais eventos são: a ativação do sistema nervoso simpático e parassimpático; produção de catecolaminas pela medula adrenal; e a liberação de neuropeptídeos e corticotropina para a glândula pituitária que por sua vez produz vários hormônios. A liberação destes fatores leva a uma depressão imunológica com diminuição do número e das funções de linfócitos e células NK. A própria depressão psicológica causa diversas alterações imunológicas como diminuição da resposta proliferativa de linfócitos T, B e células NK.

Hoje sabemos que a infecção de linfócitos humanos normais pelo HIV-1 é aumentada em meio de cultura celular quando adicionamos corticóide (ACTH), uma substância frequentemente liberada durante o estresse. Esses efeitos estão coerentes com as idéias de FERNANDES \& GELLER ${ }^{3}$ (1993) que defendem o pressuposto da existência de receptores leucocitários para hormônios e neuropeptídeos como também a possível liberação de ACTH por células do sistema imune. Esta interrelação íntima de fatores dos Sistemas Endócrino/ Nervoso Central/Imunológico reforça a idéia de que os efeitos do estresse atingem diretamente as defesas específicas do ser humano aos diversos antígenos.

Mais especificamente em relação às pessoas com HIV, o estresse é um fator que pode ter grande influência na evolução clínica desta infecção. Alguns marcadores biológicos desta evolução clínica têm sido estudados a fim de proporcionar melhor embasamento para o prognóstico e tratamento/prevenção de possíveis complicações. A relação anteriormente citada do sistema imune com o estresse pode ser avaliada a partir de parâmetros clínicos, imunológicos e psicológicos. Clinicamente, vários sinais e sintomas de estresse podem ser detectados partindo-se da anamnese e de exame físico. LIPP \& MALAGRIS ${ }^{5}$ (1989) citam alguns sinais: apatia, depressão, desânimo, sensação de desalento, hiperssensibilidade emotiva, irritabilidade, raiva, ira, ansiedade. As mesmas autoras defendem ainda que "o estresse não só se manifesta por esses sintomas, mas também ele contribui para a etiologia de várias doenças mais graves" (1989, p. 251), mostrando que os aspectos psicológicos estão intimamente relacionados com diversos sintomas clínicos psicossomáticos.

Assim, uma pesquisa sobre este tema, justificase não só pela situação e relações descritas anteriormente, como também pelos crescentes estudos na área do estresse que têm mostrado a grande importância deste fator na evolução de doenças infecciosas, neoplásicas e auto-imunes. Este trabalho poderá trazer subsídios que possibilitem pessoas e instituições que lidam com esta realidade promover, através da educação e acompanhamento clínico, uma melhor qualidade de vida para as pessoas infectadas pelo HIV em nosso meio.

Desta forma, delimitamos dois objetivos para o nosso estudo: Detectar os agentes estressores que afetam 
a pessoa com HIV/AIDS e Identificar o modo pelo qual a pessoa com AIDS maneja as situações de estresse.

\section{MATERIAL E MÉTODO}

O estudo foi desenvolvido em uma Organização Não Governamental (ONG) localizada na cidade de Fortaleza que presta assistência a portadores do HIV. A assistência ali prestada compreende atendimento psicológico, suporte espiritual, técnicas de relaxamento, atividades grupais, suporte alimentar e subsídio para transporte. A instituição caracteriza-se essencialmente como um Hospital-Dia. A coleta de informações foi realizada no período do mês de junho de 1996. Os sujeitos da pesquisa foram indivíduos do sexo masculino soropositivos ao HIV, acompanhados na referida ONG. A coleta de dados compreendeu 2 etapas:

- No primeiro momento foi realizada uma entrevista com os sujeitos que concordaram em participar da pesquisa. Neste momento pretendeu-se coletar dados de identificação, reações ante à soropositividade, postura ante à vida e à doença e vivência atual de situações estressantes.

- O $2^{\circ}$ momento compreendeu uma fase de intervenção na qual foi desenvolvido com os sujeitos da pesquisa um curso, na forma de oficinas, em que foram trabalhados conceitos básicos relacionados com a ocorrência de estresse em indivíduos com problemas de saúde e discussões sobre situações cotidianas que demandam um melhor manejo do estresse.

O material coletado nas entrevistas foi trabalhado seguindo o método de análise de conteúdo, usando mais especificamente a técnica de análise temática.

Foram tomadas as falas dos sujeitos, fazendo-se uma pré-análise, o que gerou um primeiro agrupamento dos conteúdos. A partir disso, procedeu-se à categorização dos temas presentes no discurso e que remetiam aos conceitos centrais do estudo como: estresse, agentes estressores, reações à soropositividade, padrões de relacionamento, entre outros.

Finalmente, os dados agrupados foram organizados em quadros onde aparecem as categorias encontradas e os estratos de discursos com elas relacionadas.

Vale salientar que um dos quadros (Quadro 7) obedeceu a uma lógica quantitativa. Neste caso foi feito um agrupamento em categorias e subcategorias e sua freqüência de aparecimento dos mesmos nos discursos, sem entretanto transcrevê-los, uma vez que, de alguma forma, o conteúdo dos mesmos já havia sido contemplado nos demais quadros.

\section{RESULTADOS}

Os sujeitos da pesquisa foram 11 indivíduos sendo todos do sexo masculino, com idade variando de 24 a 47 anos, sendo a maior freqüência verificada no intervalo de 30 a 36 anos (06), a qual se levarmos em consideração que o período de incubação da infecção aguda do HIV pode variar em média de 2 a 6 anos, podemos concluir que a contaminação ocorreu numa fase de adultos jovens. Do grupo estudado, 06 eram procedentes de Fortaleza e 05 do interior do estado. Pelo menos 09 indivíduos haviam mudado de endereço uma vez nos últimos dois anos, o que já configura uma situação de estresse. O nível de escolaridade variou do $1^{\circ}$ grau incompleto até o nível superior, sendo o $1^{\circ}$ grau incompleto o predominante (04). Todos afirmavam trabalhar antes de descobrirem ser soropositivos, destes apenas 03 continuam trabalhando, trazendo à tona o problema financeiro, que não é apenas o fato de estar desempregado mas também, a falta de subsídios para o próprio tratamento. Aliado a isto, temos o fato de que a renda familiar da maioria dos entrevistados (06) era de, no máximo 02 salários mínimos. De todo o grupo, 07 haviam tido conhecimento de sua soropositividade há, no máximo 03 anos. Sete deles, também já suspeitavam ser portadores do HIV quando receberam o resultado sorológico.

\section{Quadro 1 - Reação dos entrevistados ante à comunicação da soropositividade}

\begin{tabular}{|c|c|}
\hline REAÇÃO & DISCURSOS \\
\hline "FICOU FIRME" & $\begin{array}{l}\text { "Eu fiquei parado e disse pro meu } \\
\text { companheiro: Vamos cuidar da nossa } \\
\text { vida. Deixa o barco rolar" } \\
\text { "Eu tava tão consciente, tão protegido } \\
\text { que eu fiquei firme" }\end{array}$ \\
\hline $\begin{array}{l}\text { NÄO } \\
\text { ACEITAÇÄ, } \\
\text { TENTATIWA DE } \\
\text { SUICIDDO }\end{array}$ & $\begin{array}{l}\text { "Uma idéia de morte... aporrada danotícia } \\
\text { de você saber que é soropositivo é igual } \\
\text { de qualquer forma que é dada. Quando } \\
\text { eu fui receber o exame com a psicóloga, } \\
\text { fiquei anestesiada. Quando eu retornei } \\
\text { tive a idéia de suicidio. Tentei e minha } \\
\text { amiga não deixou. Depois eu rezei e tive } \\
\text { um choro copioso por vários dias" }\end{array}$ \\
\hline $\begin{array}{l}\text { TRISTEZA, } \\
\text { DEPRESSAO, } \\
\text { MEDO DE } \\
\text { MORRER }\end{array}$ & $\begin{array}{l}\text { "Pra mim a vida tinha acabado. Ainda } \\
\text { penso como se isso fosse um fantasma. } \\
\text { Aqui, as coisas melhorram, mas ainda } \\
\text { tenho quando vou transar" } \\
\text { "Foi a pior coisa, o chão sumiu, fiquei } \\
\text { fora de si } \\
\text { "Eu me espantei, fiquei muito pensativo, } \\
\text { fiquei em depressão. Aquele trauma de } \\
\text { que eu ia morrer. Um dia eu parei pra } \\
\text { pensar e pedi força a Deus pra esquecer } \\
\text { que tô com aquilo. Eu e squeci, mas } \\
\text { quando chego aqui eu relembro, mas ai } \\
\text { eu converso com o pessoal e esqueço" }\end{array}$ \\
\hline
\end{tabular}


Observando-se o conteúdo do Quadro 1, verificase que as reações dos entrevistados, quando foram comunicados sobre sua condição de soropositivos, foram de não aceitação, inconformismo com a nova condição. Isto está demonstrado nos trechos de discursos contidos no quadro em que os sujeitos relatam tristeza, depressão, medo de morrer e até tentativa de suicídio. Mesmo aqueles cujas reações foram categorizadas como "ficar firme" apresentam discursos que demonstram uma atitude de fuga ou o esforço por proteger-se da realidade revelada, o que pode ser traduzido também como não aceitação.

Vale salientar que no presente momento, saberse soropositivo não é apenas vislumbrar a possibilidade de adoecer, é também ver-se ameaçado de morrer. Portanto, estar soropositivo é estar submetido a um agente estressor permanente e intenso.

Quadro 2 - Padrão atual de relacionamento com os amigos

\begin{tabular}{|c|l|}
\hline PADRÃO & \multicolumn{1}{|c|}{ DISCURSOS } \\
\hline BOM, & "É le gal, eles me apoiam, até agora \\
PREDOMÍ́IIO DE & ninguém me criticou" \\
CONFIANÇA, & "É uma relação boa até porque eutenho \\
poucos amigos e sou muito exigente \\
AUSÊHCIA DE \\
PRECONCEITOS \\
nas minhas amizades" \\
"Merelaciono muito bem, eu conto tudo \\
pra eles. Eles não tem preconceito com \\
nada"
\end{tabular}

O Quadro 2 mostra que o padrão de relacionamento com os amigos, na maioria dos entrevistados, é bom e baseia-se em confiança. Porém, quase a metade do grupo relatou auto-isolamento ou até mesmo o fato de não revelar sua condição de soropositividade. Portanto, o relacionamento com os amigos é tão valorizado pelos soropositivos que ora escondem o próprio diagnóstico para que não sofram com o possível afastamento deles, ora tomam a iniciativa de auto-isolar-se, também pela mesma razão, uma vez que os amigos parecem não compreender tal atitude. É possível afirmar, então, que o medo de perder a proximidade com as pessoas amigas é um importante agente estressor.

Quadro 3 - Relacionamento, junto às pessoas com quem moram, após a revelação da soropositividade

\begin{tabular}{|c|c|}
\hline $\begin{array}{l}\text { COM QUEM } \\
\text { MORA }\end{array}$ & $\begin{array}{c}\text { RELACIONAMENTO APÓS A } \\
\text { REVELAÇÄO }\end{array}$ \\
\hline FAMÍLIA & $\begin{array}{l}\text { "Senti meu pai mais próximo depois da } \\
\text { soropo sitividade. Eu tenho uma immã } \\
\text { mais nova que eu não contei, mas eu } \\
\text { acho que ela limpando as coisas viu o } \\
\text { vidro de Wdex que eu tomo e chegou às } \\
\text { suas conclusões. Eu senti até ela mais } \\
\text { revoltada com o carinho que estão me } \\
\text { dando, por que ela era a queridinha da } \\
\text { casa" } \\
\text { "Acho que eles passaram a me tratar } \\
\text { melhor. Mas antes eles sempre me } \\
\text { trataram bem, acho que pelo fato de ser } \\
\text { homossexua" }\end{array}$ \\
\hline $\begin{array}{l}\text { COMPANHEIRA } \\
\text { E FILHOS }\end{array}$ & $\begin{array}{l}\text { "Na hora foi um impacto muito grande } \\
\text { pra ela e tivemos muitas mudanças na } \\
\text { nossa vida sexual, até por que ela não é } \\
\text { portadora. A gente teve que adotar } \\
\text { outras práticas. A gente transa com } \\
\text { menos freqüência" }\end{array}$ \\
\hline $\begin{array}{c}\text { MÄEE } \\
\text { COMPANHEIRO }\end{array}$ & $\begin{array}{l}\text { "Eles fic aram com pena de mim e me } \\
\text { deram uma casa pra morar" } \\
\text { "Na época eu morava com meus pais e } \\
\text { eu que me afastei por causa dos } \\
\text { vizinhos" }\end{array}$ \\
\hline MÄE E IRMÄ & $\begin{array}{l}\text { "Elas não sabem" } \\
\text { "O comportamento dela (Irmã) ficou } \\
\text { igual, eu foi que mudei porque ela tinha } \\
\text { duas crianças e eu brincava muito com } \\
\text { elas. Ai eu tive medo de ac ontec er } \\
\text { alguma coisa" }\end{array}$ \\
\hline PARCEIRO & $\begin{array}{l}\text { "Quando recebi o diagnóstico eu } \\
\text { morava com um companheiro que } \\
\text { também era soropositivo e nossa } \\
\text { relação continuou numa boa" }\end{array}$ \\
\hline SOZINHO & -------- \\
\hline
\end{tabular}

Examinando-se o Quadro 3, verificamos que o relacionamento com os familiares após a revelação da soropositividade, variou bastante entre os entrevistados. A maioria dos relatos retrata atitudes passivas com implicações restritivas desde queda no padrão de vida, que por si só já é um agente estressor, até o autoisolamento, a fuga de problemas e medo de contaminar terceiros. Todos estes aspectos acabam por configurar 
situações em que o manejo do estresse se faz algo imprescindível para uma melhor convivência com a doença, visto que a família é a base afetiva e social das pessoas, e a falta de apoio desta pode trazer conseqüências psíquicas graves.

\section{Quadro 4 - Preocupações atuais e formas de enfrentamento}

\begin{tabular}{|c|c|}
\hline MAIOR PREOCUPAÇÃO & $\begin{array}{c}\text { FORMAS DE } \\
\text { ENFRENTAMENTO }\end{array}$ \\
\hline $\begin{array}{l}\text { COMPORTAMENTO } \\
\text { DE RISCO DO } \\
\text { PARCEIRO }\end{array}$ & $\begin{array}{l}\text { "O que eufaçoé pelejar com ele } \\
\text { prá ele parar de fazer } \\
\text { estravagância" }\end{array}$ \\
\hline $\begin{array}{c}\text { MEDO DE SE } \\
\text { ENVOLVER COM } \\
\text { ALGUÉM } \\
\text { SOROPOSITIVO }\end{array}$ & $\begin{array}{l}\text { "Sou super alegre. Através da } \\
\text { alegria" }\end{array}$ \\
\hline $\begin{array}{c}\text { MEDO DE PIORAR E } \\
\text { MORRER }\end{array}$ & $\begin{array}{l}\text { "Saio, vou pra uma praça pólo } \\
\text { de lazer ou vou pra casa de um } \\
\text { amigo. Aí aquilo passa" } \\
\text { "Eu saio vou à praia. Vou prá } \\
\text { casa de um amigo meu de } \\
\text { confiança. Tento esquecer" }\end{array}$ \\
\hline $\begin{array}{l}\text { MEDO DA SOLIDÃOE } \\
\text { DO PRECONCEITO }\end{array}$ & "Fumo à noite. Assisto TV" \\
\hline $\begin{array}{c}\text { DIFICULDADES } \\
\text { FINANCEIRAS, } \\
\text { DESEMPREGO, NÄO } \\
\text { TER } \\
\text { APOSENTADORIA }\end{array}$ & $\begin{array}{l}\text { "Eu fico martelando bastante e } \\
\text { ultimamente eu parti para pedir } \\
\text { ajuda àminha familia ou amigos. } \\
\text { Eu procuro não me acomodar" } \\
\text { "Eu vou andar para me distrair, } \\
\text { conversar, ouvir música" } \\
\text { "Eu procuro esquecer que ela } \\
\text { existe. Procuro ler pra distrair a } \\
\text { mente" } \\
\text { "Fico pensando nisso, choro } \\
\text { muito, me deprimo. To } \\
\text { terminando um curso de } \\
\text { cabelereiro pra ter uma renda a } \\
\text { mais e poder ajudar meu pai" }\end{array}$ \\
\hline $\begin{array}{l}\text { RELACIONAMENTO } \\
\text { AFETIVO NÄO } \\
\text { RESOLVIDO }\end{array}$ & $\begin{array}{l}\text { "Começo a trabalhar, ocupar } \\
\text { minha cabeça prá esquecer" }\end{array}$ \\
\hline NENHUMA & - \\
\hline
\end{tabular}

Podemos verificar no Quadro 4 que a maioria das preocupações atuais dos entrevistados relaciona-se ao sentimento de medo das conseqüências das doenças como morrer, mudar a própria aparência, solidão e preconceito. Constatamos, também, que as formas de enfrentamento não são adequadas ou eficazes, pois ou ficam pensando no problema, ou fumam, ou saem, ou esforçam-se por estar sempre alegre, havendo ainda, os que trabalham excessivamente para esquecer a própria condição de saúde. Predomina, portanto, um esforço de fuga. Isso aponta para a necessidade de os profissionais de saúde oferecerem um espaço para discussão sobre formas eficazes e apropriadas de enfrentamento do estresse, sempre adequadas à situação de cada pessoa.

\section{Quadro 5 - Padrão de vida sexual atual dos entrevistados}

\begin{tabular}{|c|c|}
\hline PADRÃO & ESPECIFICIDADES \\
\hline $\begin{array}{c}\text { ATIVA COM } \\
\text { PARCEIRO FIXO }\end{array}$ & $\begin{array}{l}\text { "Eu gosto da L..., a gente se dá bem em } \\
\text { tudo" } \\
\text { "Tá bem. Só por causa das brigas. Ele } \\
\text { não quer que eu ande em boites" } \\
\text { "Bom. Não é todo dia. Só quando a } \\
\text { mãe dele não tá" }\end{array}$ \\
\hline $\begin{array}{c}\text { ATIVA SEM } \\
\text { PARCEIRO FIXO }\end{array}$ & $\begin{array}{l}\text { "Cada vez mais louca. Coisa melhor do } \\
\text { que sexo, só mais sexo. Quando não } \\
\text { aparece eu fico louco" } \\
\text { "Eu tenho relação fora do âmbito } \\
\text { conjugal, só que é raro. A relação com } \\
\text { minha companheira está boa, só que } \\
\text { com menos frequê̂ncia" }\end{array}$ \\
\hline $\begin{array}{c}\text { ATIVA } \\
\text { ESPORADICA } \\
\text { OU SEM } \\
\text { ATIVIDADE }\end{array}$ & $\begin{array}{l}\text { "Parada totalmente. Em julho faz um } \\
\text { ano, não por falta de pretendente. Eu } \\
\text { não consigo me atrair por alguém. } \\
\text { Tenho medo de passar prá alguém" } \\
\text { "Desde que eu de scobri que tenho } \\
\text { AIDS, eu só faço masturbação porque } \\
\text { eu fico pensando que quando eu me } \\
\text { relaciono, a outra pessoa tem AIDS. O } \\
\text { doutor falou que é pior prá gente e ai } \\
\text { eu tenho medo" } \\
\text { "Estou sem ninguém, mas não procuro } \\
\text { ninguém, mas se aparecer alguém eu } \\
\text { pego" }\end{array}$ \\
\hline
\end{tabular}

Os dados do Quadro 5 demonstram que o padrão de vida sexual atual dos sujeitos da pesquisa passou por mudanças ou sofreu restrições, sejam elas em termos de freqüência ou de qualidade. Assim, podemos perceber, pelo exame deste quadro, que a maioria deles tem vida sexual esporádica ou ativa com restrições. Foram poucos aqueles que relataram que a sexualidade permaneceu como antes. Existem, ainda, aqueles que relatam manter relações sexuais sem um parceiro fixo. De uma maneira geral, os relatos apontam que os sujeitos percebem a atividade sexual como algo que ajuda a manter um certo 
"sentido de normalidade" e a ausência desta, traz uma angústia crescente, provocando uma unidade de estresse que é bastante comum e grave pelo isolamento daí resultante.

\section{Quadro 6 - Projetos de vida dos entrevistados}

\begin{tabular}{|c|c|}
\hline CATEGORIA & ESPECIFICIDADES \\
\hline $\begin{array}{l}\text { REALIZACÄO } \\
\text { PESSOALE } \\
\text { MATERIAL }\end{array}$ & $\begin{array}{l}\text { "Desde que eu era bom eu tinha um } \\
\text { sonho que era gravar um disco e eu } \\
\text { ainda não consegui (..) eu vou morrer } \\
\text { com esse sonho" } \\
\text { "Se Deus me der muitos anos de vida, } \\
\text { eu tenho: de organizar o lugar onde } \\
\text { vivo" } \\
\text { "Terminar meu curso de cabelereiro e } \\
\text { ter uma renda prá superar meus } \\
\text { problemas e ajudar minha mãe" } \\
\text { "Morar só. Eu me smo ter minha } \\
\text { responsabilidade. Ter } \\
\text { independência" } \\
\text { "Eu tenho muitos sonhos. Eu tenho } \\
\text { muitas coisas prá comprar pra casa, nem } \\
\text { que eu morrerlogo depois. Eu deixo prá } \\
\text { minha irmã. Um grande sonho que eu } \\
\text { tenho é de ter uma casa própria e eu } \\
\text { tenho fé em Deus que vou conseguir" }\end{array}$ \\
\hline SOBREVIVÊNCIA & $\begin{array}{l}\text { "Permanecer da forma como estou. Não } \\
\text { piorar. Wiver" } \\
\text { "de me sentir bem da depressão dos } \\
\text { me dic amentos que eu tomo. É } \\
\text { deprimente a quantidade" }\end{array}$ \\
\hline $\begin{array}{l}\text { NÄO TEMI } \\
\text { PROJETOS }\end{array}$ & $\begin{array}{l}\text { "Eu acho que não vale a pena porque } \\
\text { eu não seiquanto tempo tenho de vida" }\end{array}$ \\
\hline
\end{tabular}

Os projetos de vida dos entrevistados estão categorizados no Quadro 6 como de realização pessoal e material, de sobrevida e sem projetos. A maioria das respostas recaiu sobre projetos de realização pessoal e material como ter uma casa, conseguir emprego ou aposentadoria. Em seguida vêm as respostas relativas a ter uma longa sobrevida, não piorar ou se curar. Por último há uma pessoa sem projetos. No geral constatamos na coleta de dados que todos os projetos eram imediatistas ou de curto prazo, apontando para um temor dos sujeitos de não poder realizá-los. Sobre isso é possível afirmar que a incurabilidade da AIDS pesa sobre os indivíduos soropositivos como agente estressor, limitando seus projetos para o futuro.
Quadro 7 - Agentes estressores identificados no grupo

\begin{tabular}{|c|c|}
\hline AGENTES ESTRESSORES & FREQ.ABSOL. \\
\hline PERDAS & 11 \\
\hline - Morte do outro & 07 \\
\hline - Solidão & 04 \\
\hline MUDANÇAS & 17 \\
\hline - Piora/morte & 05 \\
\hline - Saúde de outrem & 08 \\
\hline - Hábitos pessoais & 03 \\
\hline - Residência & 01 \\
\hline REALIZAÇŌES & 02 \\
\hline - Atividade desejada & 01 \\
\hline $\begin{array}{l}\text { - Revelou sua soropositividade para } \\
\text { quem o contaminou }\end{array}$ & 01 \\
\hline DIFICULDADES & 11 \\
\hline - Afetivas & 02 \\
\hline - Financeiras & 07 \\
\hline - Relacionamento pessoal & 01 \\
\hline - Barreiras na Instituição & 01 \\
\hline
\end{tabular}

O Quadro 7 consolida quantitativamente outros agentes estressores identificados no grupo. $\mathrm{O}$ estresse por mudança foi o mais relatado, confirmando que a condição de soropositividade traz muita instabilidade à vida de uma pessoa. O número de mudanças é ao mesmo tempo grande e intenso. As dificuldades e as perdas também se fizeram bastante presentes nos relatos. As dificuldades são principalmente afetivas e financeiras, enquanto que as perdas estão ligadas ao fato de conviver com a morte de conhecidos e perda de vínculo com amigos e familiares. Tais agentes estão presentes intensamente nos relatos demonstrados nos quadros anteriores, determinando um grau elevado e constante de estresse que contribui diretamente para o desenvolvimento mais acelerado da doença segundo alguns estudos já referidos anteriormente. 


\section{CONSIDERAÇÕES FINAIS}

Os resultados deste estudo não podem ser generalizados, pois restringem-se a um grupo pequeno de indivíduos. Mesmo assim, dado o caráter cosmopolita da AIDS e sua incurabilidade, provavelmente serão encontrados resultados semelhantes em vários aspectos, mesmo em pesquisas que venham a ser desenvolvidas em realidades diferentes. Podemos concluir, que o grupo estudado demonstrou a presença de graves agentes estressores, cujos principais foram: mudanças, medo da morte, dificuldades financeiras e problemas afetivos. Nos relatos apresentados, os sujeitos mostraram-se conscientes de tais estressores porém, os mecanismos usados para lidar com esse estresse não podem ser considerados adequados uma vez que se baseiam em fuga e repressão, que além de tudo são usados não como uma forma de adaptação ou aceitação, mas sim, como uma forma de evitar o enfrentamento do problema. Sem dúvidas, o desenvolvimento de trabalhos educativos que propiciem uma orientação sobre estresse e seu manejo se fazem imprescindíveis para melhorar a qualidade de vida das pessoas que vivem com HIV/AIDS.

\section{PEOPLE LIVING WITH HIV: STRESS AND WAYS OF FACING ILLNESS}

A study about the stress influence in the life of people with the HIV/AIDS positive was carried out with eleven HIV positive men, in order to analyse the stress and the daily life of HIV people. Using interviews as a way to collect data, we found that many of these individuals had been submitted to stress situations such as: social and sexual changes, material losses, loneliness and fear of dying. The ways of facing up these situations were escaping from reality, being happy at all costs and trying to forget the illness. We concluded that there is a need to prepare them to face the stress, and also for an effective intervention from the health profissionals in this question.

KEY WORDS: AIDS, stress, HIV

\section{PERSONAS VIVIENDO CON VIH: ESTRÉS Y SUS FORMAS DE ENFRENTAMIENTO}

Estudio sobre la influencia del estrés en la vida de la persona con VIH/SIDA, realizado con once hombres seropositivos tiendo por objetivo analizar la relación entre el estrés y el cotidiano de las personas seropositivas. Usando como técnica de colecta la entrevista, encontramos que muchos de los entrevistados ya pasaron o vivenciaron situaciones estresantes como: modificaciones sociales y sexuales, pérdidas materiales, soledad y miedo a la muerte. Las formas de enfrentamiento del estrés variaron entre: fuga, estar alegre siempre y intentar olvidar. Concluimos que existe la necesidad de prepararse para enfrentar el estrés, y también, una intervención efectiva de los profesionales de salud nesta cuestión.

TÉRMINOS CLAVES: SIDA, estrés, VIH

\section{REFERÊNCIAS BIBLIOGRÁFICAS}

01. ABBAS, A.; LiChTMAN, A.; POBER, J. Imunodeficiências congênitas e adquiridas. In: Imunologia celular e molecular. Rio de Janeiro: Revinter, 1995. Cap. 19, p. 401421.

02. COSTA, J.R.; DAMIANO, A.; RÚBIO, R. La infección por el vírus de la inmunodeficiencia humana: patogenia, diagnóstico y tratamiento. Madrid: Ministerio de Sanidad y Consumo, 1992.

03. FERNANDES, J.T.; GELLER, M. Funções hormonal e sensorial do sistema imunológico. J. Bras. Med., v. 65, n. 4, p. 185-190, out. 1993
04. GONDIM, R.; MIRANDA, K.; ALLEN, C. Manual do multiplicador para prevenção da AIDS. Ceará: Grupo de Apoio à Prevenção à AIDS, 1993.

05. LIPP, M.N.; MALAGRIS, L.N. Manejo do estresse. In: RANGÉ, Bernard (org.). Psicoterapia comportamental e cognitiva, Campinas: Editorial Psy, 1989. p. 279-292.

06. MANN, J.; TARANTOLA, D.J.M.; NETTER, T.W. A AIDS no mundo. Rio de Janeiro: Relume Dumará/ABIA, 1993.

07. PARKER, R. et al. A AIDS no Brasil. Rio de Janeiro: Relume Dumará/ABIA/IMS, UERJ, 1994. 